\title{
RASSENTAMENTO DA COMUNIDADE TUXÁ MÃE RODELAS: ACORDOS E CONVÊNIOS
}

\author{
Erêndira Santos da Silva'; Eurelino Teixeira Coelho Neto ${ }^{2}$; \\ 1. Bolsista PROBIC/UEFS, Graduanda em Licenciatura em História, Universidade Estadual de Feira de Santana, e- \\ mail: erendirasilva20@gmail.com \\ 2. Orientador, Departamento de Ciências Humanas e Filosofia, Universidade Estadual de Feira de Santana, e-mail:
}

\section{PALAVRAS-CHAVE: Território, lutas sociais, memória}

\section{INTRODUÇÃO}

O grupo étnico Tuxá do Submédio do Rio São Francisco, como se auto identificam “Índios Tuxá da Nação Proká, do Arco, Flecha e Maracá, Malakutinga Tuá”, são parte e sujeitos ativos das lutas que se processaram nas calhas do rio São Francisco (19681994), com a execução de grandes obras hidrelétrica, num período de crise estrutural do capitalismo. O objetivo dessa pesquisa é analisar os impactos no modo de vida da comunidade Tuxá com a instalação da Usina Hidrelétrica-UHE Luiz Gonzaga e os projetos de reassentamento daí estabelecidos.

\section{MATERIAL E MÉTODOS OU METODOLOGIA (ou equivalente)}

Essa pesquisa se alicerça na análise documental de fontes disponíveis no Acervo Alcides Modesto, que reúne "[..]um testemunho documental da vida de Alcides Modesto, incluindo suas origens familiares, sua vida sacerdotal, as lutas populares, os mandatos legislativos"1; e do Arquivo Rio de Memória, em poder do Laboratório de História e Memória da Esquerda e das Lutas Sociais-LABELU.

\section{RESULTADOS E/OU DISCUSSÃO (ou Análise e discussão dos resultados)}

Analisar os impactos gerados pela construção da UHE de Itaparica aos Tuxá, e os projetos de reassentamentos firmados nos coloca o desafio de compreender em que plano político se realizou o projeto de eletrificação e o momento de "ativação política" desse grupo étnico. Buscamos não realizar um estudo da etnogênese desses indígenas, nem dos rituais xamânicos, e do cotidiano com suas práticas de sociabilidades, já feitos pelas áreas de conhecimento vizinhas como a Arqueologia, Antropologia e Etnologia, mas de como esse universo simbólico e social pode nos apresentar caminhos para compreendermos a dimensão do projeto em curso e as experiências históricas naquele território.

Os Tuxá, na década de 1980, viviam numa aldeia ao lado da cidade de Rodelas-Ba e na Ilha da Viúva, que era a reserva indígena, e servia como espaço de produção, cultivo e de suas práticas ritualísticas. Essas áreas contíguas ficavam na divisa entre Bahia e Pernambuco, no trecho Submédio do Rio São Francisco. Esse grupo étnico e demais ribeirinhos foram afetados pela usina hidrelétrica Luiz Gonzaga, antes denominada de Itaparica, que entrou em operação em 1988 e inundou cerca de 834,0 Km², deslocando

1 COELHO, Eurelino et al. UM RIO DE LUTAS: História e memória dos movimentos sociais no Submédio São Francisco (1968-1994), pp. 27 
compulsoriamente mais de 40.000 pessoas, dentre eles 1.200 indígenas Tuxá. Dos municípios atingindo, três foram no estado da Bahia: Chorrochó, Rodelas e Glória; e quatro em Pernambuco: Belém do São Francisco, Floresta, Petrolândia e Itacuruba.

A mudança espacial deste território, assim como a constituição de um novo, gerou também mudanças sociais. Considerando que "o social e o espacial são indissociáveis", o deslocamento refletiu sobre o modo de produzir e reproduzir a vida de inúmeros ribeirinhos. Os Tuxá são parte desse processo. É diante dessas circunstâncias que as questões da territorialidade, de quais caminhos seguir, de onde ser reassentado, foram colocadas na arena de negociação. A luta pelo território indígena estava pautada no valor de uso da terra, e da relação simbiótica entre o sagrado e o território, partes constitutivas do ser indígena e Tuxá, mas, que foram considerados como elementos insignificantes por aqueles responsáveis pelos empreendimentos em transcurso.

O primeiro convênio celebrado entre a CHESF e a Fundação Nacional do ÍndioFUNAI visando o reassentamento da comunidade Tuxá, firmado em 1986, estabelece as condições e as formas de reassentamento. No parágrafo único, do artigo $1^{\circ}$, declara que reassentará apenas a população cadastrada no Departamento de Implantação de Reservatório até 30 de abril de $1987^{2}$ e moradora na área do reservatório, ou seja, os membros das famílias que migraram para trabalhar em outras cidades não teriam direito.

Os Tuxá foram divididos em três grupos, o que resultou em projetos de reassentamentos diferentes, definidos nas alíneas 1 e 2 do artigo $2^{\circ}$ do convênio, 94 famílias foram transferidas para Pernambuco e 98 ficaram na Bahia, na Nova Rodelas, como podemos observar de forma detalhada no "Primeiro Relatório do Projeto de Levantamento das Áreas Indígenas do Submédio São Francisco e sua Relação com o Sindicalismo Local" elaborado em 1993, por José Maurício Andion Arruti. Esse relatório, resultado de uma pesquisa de campo, apresenta como ficou a divisão dos indígenas Tuxá "Os Tuxá de Itacuruba houve transferência para Inajá-PE, no caso dos Tuxá de Rodelas houve transferência para duas novas áreas”. Em relação a esses últimos, as negociações resultaram em conflitos políticos levando à repartição do grupo $^{3}$. Vejamos

Sob a liderança do então Cacique Manoel Eduardo da Cruz (Bidu) e o pajé Armando Gomes Tuxá, um grupo de índios Tuxá (de Nova Rodelas) opta pelo reassentamento em Riacho do Bento, área que em passado remoto, fora habitada pelos Tuxá e que está situada a aproximadamente em $20 \mathrm{~km}$ da sede da cidade de Nova Rodelas, caracterizada como caatinga e possuindo 4.000 há $^{4}$.

O segundo grupo liderado por Manoel Novaes, intitulado cacique, decide-se pelo estabelecimento no município de

\footnotetext{
${ }^{2}$ CONVÊNIO que entre si celebram a CHESF e a FUNAI. Recife, 1986.p;7

3 ARRUTI, José M. A.; Primeiro Relatório do Projeto de Levantamento das Áreas Indígenas do Submédio São Francisco e sua Relação com o Sindicalismo Local. 1993, p. 23

${ }^{4}$ Ibid, p. 23
} 
Ibotirama, a $1.200 \mathrm{~km}$ de Rodelas, onde a CHESF viria adquirir o reassentamento deste grupo a Fazenda Morrinhos e Oteiros, terras às margens do Rio São Francisco, com aproximadamente $2.019 \mathrm{ha}^{5}$.

A cláusula terceira estabelece que as famílias reassentadas pelas áreas do Riacho do Bento, que será inundada, receberão as seguintes indenizações:

a) Das acessões, culturas e benfeitorias que possuem na área a ser inundada pelo reservatório, exceto a casa residencial; b) uma casa em alvenaria, com instalações elétricas e hidro sanitárias; c) material e mão de obra para complementar o esforço de construção da casa própria, por parte das famílias que não tem moradia; d) um hectare destocado e gradeado, destinado à irrigação das culturas que venham a ser desenvolvidas; e) transporte rodoviário dos respectivos bens, do local de origem, em Itaparica, para as áreas de reassentamento ${ }^{6}$.

No período em que o relatório Arruti acima citado foi lançado, seis anos depois do estabelecimento do reassentamento, a CHESF não tinha cumprido o cronograma de realização das obras, nem instalou a infraestrutura necessária para a retomada da agricultura em Ibotirama. Os Tuxá da Nova Rodelas, reivindicavam que o primeiro acordo fosse modificado, ampliando para quatro hectares por família. A carta encaminhada por Alcides Modesto, deputado federal e assinada pelo Cacique Raul Valério ao Ministro de Minas e Energia Dro Paulino Cícero solicitando que os prazos fossem respeitados indica como os acordos foram protelados: "A implantação do projeto e o cumprimento do convênio (...) eram para serem finalizados em um ano e meio, pois bem, já se passaram seis anos ${ }^{7}$. O Outro exemplo, foram as verbas de manutenção temporária, estabelecidas no convênio pela CHESF, que garantia dois salários mínimos e meios por famílias, até que fossem implantado o projeto de irrigação, porém, “ a partir de 1988 sem justificar sua atitude às famílias indígenas, com a conivência da FUNAI, a CHESF reduziu a taxa assistencial que reza a cláusula quarta"8.

A construção da barragem e distribuição das suas linhas de transmissão não foram aceitas pela maioria dos atingidos de forma passiva. Eles enfrentaram a "besta-fera" $\mathrm{e}$ lutaram pelo direito à terra e/ou medidas compensatórias que se apresentam de formas diversas, expressando a própria heterogeneidade dos grupos sociais que compunham

\footnotetext{
${ }^{5}$ Ibid, p. 25

${ }^{6}$ Convenio que entre si celebram a CHESF e a FUNAI. Recife. 1986.p;8

${ }^{7}$ Carta encaminhada pelo Deputado Alcides ao Ministro de Energia. 1993.p.4

8 Ibid, p.4

${ }^{9}$ SILVA, J. V. S. O povo versus a "Besta-Fera": o Polo Sindical dos Trabalhadores Rurais do Submédio São Francisco -Pe/Ba - na organização do movimento dos trabalhadores ribeirinhos atingidos pela barragem de Itaparica - BA/PE - (1976-1986). Dissertação (Dissertação em História) - UEFS. Feira de Santana, p. 254. 2018.
} 
essa região - os grupos étnicos, trabalhadores do campo, posseiros, fazendeiros e os políticos locais.

\section{CONSIDERAÇÕES FINAIS (ou Conclusão)}

A construção de barragens, na década de 1980, era uma das estratégias de dinamização do setor elétrico no país, e ocorreu em paralelo ao desenvolvimento e diversificação da indústria. A lei $\mathrm{n}^{\circ}$ 6.001, de 19 de dezembro de $1973^{10}$, abria prerrogativas para a construção de barragens em áreas indígenas, pois permitia a União intervir na realização de grandes obras públicas de interesse do desenvolvimento nacional. As fontes analisadas demonstram que os acordos foram protelados e os indígenas tiveram suas bases produtivas usurpadas e foram inseridos numa outra lógica de viver e relacionar com a terra, como também tiveram sua identidade, o ser Tuxá, ameaçada, pois as novas terras não poderiam assegurar a sacralidade.

\section{REFERÊNCIAS}

COELHO, Eurelino et al. UM RIO DE LUTAS: História e memória dos movimentos sociais no Submédio São Francisco (1968-1994). - Feira de Santana: UEFS, 2014, 27p.

COELHO, Eurelino. Hipóteses sobre a luta de classes no capitalismo contemporâneo. In: COELHO, Eurelino. PACHECO, Larissa P. B (org.). Lutas Sociais, intelectuais e poder: Problemas de História Social. - Feira de Santana: UEFS Editora, 2012, p.274

SILVA, J. V. S. O povo versus a "Besta-Fera": o Polo Sindical dos Trabalhadores Rurais do Submédio São Francisco -Pe/Ba - na organização do movimento dos trabalhadores ribeirinhos atingidos pela barragem de Itaparica - BA/PE - (1976-1986). Dissertação (Dissertação em História) - UEFS. Feira de Santana, p. 254. 2018.

\section{FONTES}

ARRUTI, José M. A.; Primeiro Relatório do Projeto de Levantamento das Áreas Indígenas do Submédio São Francisco e sua Relação com o Sindicalismo Local. 1993 Convenio que entre si celebram a CHESF e a FUNAI. Recife, 1986.p;8

Carta Ministro de Energia. Acervo Alcides Modesto. 1993, p.4

\footnotetext{
${ }^{10}$ BRASIL. Lei $\mathrm{n}^{\circ}$ 6.001, de 19 de dezembro de 1973. Dispõe sobre o Estatuto do Índio. Diário Oficial da república Federativa do Brasil. Brasília, DF 21.12.197. Disponível em <http://www.planalto.gov.br/ccivil_03/leis/L6001.htm>. Acesso em 29 de jul de 2018.
} 